\title{
Investigating the Feasibility of Open Development of Operations Support Solutions
}

\author{
C.R. Gallen, J. S. Reeve \\ University of Southampton \\ Hampshire, England \\ [cg02r,jsr]@ecs.soton.ac.uk
}

\begin{abstract}
The telecommunications Operations Support Systems supply chain must address many stakeholders: R\&D, Product and Requirements Management, Purchasing, Systems Integration, Systems Administration and Users. While the management of next generation networks and services poses significant technical challenges, the present supply chain, market configuration, and business practices of the OSS community are an obstacle to rapid innovation. Forums for open development could potentially provide a medium to shorten this supply chain for the deployment of workable systems. This paper discusses the potential benefits and barriers to the open development of OSS for the telecommunications industry. It proposes the use of action research to execute a feasibility study into the open development of OSS software solutions within an industry wide Open OSS project.
\end{abstract}

\section{Keywords}

Open Source, NGOSS, OSS/J, Action Research, OSS, Operations Support Systems, Systems Integration, Requirements Management

\section{Introduction}

In recent years the phenomena of open source and collaborative development between organisations has delivered some spectacular successes such as LINUX and Apache and aroused considerable interest in the software community. The telecoms industry has historically been very conservative in its approach to software development. As a result, it can be argued that the industry has been slow to benefit from software trends originating in other industries.

Our research interest concerns whether open source development can provide an alternative mechanism for the telecoms industry to solve network management problems. For our purposes, the Wall Street Journal has coined a simple definition of open source software which avoids an obfuscated discussion on the nature of software licensing; 
Open-source programs share programming instructions usually

kept secret in commercial software. Such programs are created and improved by global groups of programmers and users. [1]

Ramande's 'The Cathedral and The Bazaar'.[2] is perhaps the most famous challenge to the notion that only closed development techniques can deliver good quality software. However a growing community of other researchers have been actively investigating the viability and benefits of open software as an alternative to COTS (Custom Off The Shelf) solutions $[3,4,5,6,7,8,9]$ It is significant, though, that as far as we can tell, none of these groups are focusing on the potential for Open Source in the Telecoms Operations Support System (OSS) environment.

We consider that open source and collaborative development could have significant implications for the telecommunications industry if a community was established for the development of open OSS Software. In order to test this assertion, we believe a cross industry action research pilot project needs to be established for the purpose of delivering a useful OSS solution using collaborative / open source techniques. This would then act as a vehicle for researching the viability of this approach for wider OSS software development.

The remainder of this paper is organized as follows. First we discuss some of the reasons why OSS development continues to be a major issue within the Telecommunications industry. Then we analyse where we think collaborative development might help. Next we describe the Open OSS project. Finally we conclude and present directions for future work.

\section{The OSS Development Problem}

\subsection{The Market for Operations Support Systems}

OSS Observer's study of the OSS market [10] reveals that the global spending on Operational Support Systems within the telecoms industry is around $\$ 30$ billion dollars per year (about $3 \%$ of total telecoms revenue) with about $2 / 3$ of this being spent on custom developed systems and $1 / 3$ on COTS software. Some 200,000 IT professionals are employed globally by service provider IT departments, many of whom are working on internally developed solutions. The majority of the $\$ 10$ billion dollars COTS OSS market is accounted for by only the top 100 service providers and when deployed by these service providers the COTS products are often heavily modified before use. Against this background, it can be seen that the lion's share of OSS development activity in the telecoms industry is still done internally by service providers. Over the last 20 years, COTS solutions have made significant inroads but these solutions still only account for $1 / 3$ of global OSS software development.

OSS Observer [11] further reports that in developing countries such as India, Indonesia and Vietnam, low labour rates limit the commercial OSS opportunities for global OSS ISVs. In many of these countries, alternative low cost software solutions have emerged because operators are unwilling or unable to afford the price of the applications used by operators in the West. These solutions are often supplied internally or from other emerging countries; a fact evidenced by several 
TM Forum Catalyst projects which have showcased non-mainstream capabilities originating in the CIS or India. Global market surveys do not necessarily reflect the contribution these solutions make because they are internal or low budget.

In the developed world users of OSS systems can be characterised in three tiers. In the primary tier are the large national and translational incumbents many of which are privatised PTTs. In the secondary tier are smaller alternative operators who mostly compete with the primary tier in the high value business market. In the third tier are niche players who target very specific opportunities - often adding value on top of the wholesale infrastructure of the incumbents. A simple characterisation of these tiers is given in Table 1.

In general the market for telecoms OSS systems is a relatively small pool compared to other markets for commercial software such as e-business. This is evidenced by the fact that the Telemanagement Forum, which is the premier industry body supporting Service Provider OSS standardisation, has only 370 corporate members including suppliers.

Table 1: Purchasing patterns of Telecoms operators

\begin{tabular}{|c|c|c|c|}
\hline Market & Internal $R \& D$ & Product Purchasing & Other factors \\
\hline $1^{\text {st }}$ Tier & $\begin{array}{l}\text { - } \text { Significant } \\
\text { Internal R\&D } \\
\text { - Historically used } \\
\text { internal solutions } \\
\text { - Big integration } \\
\text { \& support teams }\end{array}$ & $\begin{array}{l}\text { - May use set of 'best in } \\
\text { Class' COTS products } \\
\text { - Will modify selected } \\
\text { products extensively } \\
\text { - Often do own } \\
\text { integration }\end{array}$ & $\begin{array}{l}\text { - Have a historical } \\
\text { legacy of } 100 \text { 's of } \\
\text { systems to } \\
\text { integrate with new } \\
\text { services }\end{array}$ \\
\hline $\begin{array}{l}2^{\text {nd }} \text { Tier } \\
(A O)\end{array}$ & $\begin{array}{l}\text { - Limited or no } \\
\text { R\&D. }\end{array}$ & $\begin{array}{l}\text { - Will use set of 'best in } \\
\text { Class' COTS products } \\
\text { - Will spend on products } \\
\text { but not on R\&D } \\
\text { - Often partner with large } \\
\text { SIs for integration }\end{array}$ & $\begin{array}{l}\text { Finding they have } \\
\text { created a legacy } \\
\text { architecture } \\
\text { through hasty start- } \\
\text { up purchasing } \\
\text { decisions }\end{array}$ \\
\hline $\begin{array}{l}3^{\text {rd }} \text { Tier } \\
\text { (Niche) }\end{array}$ & $\begin{array}{l}\text { No R\&D but } \\
\text { will use any } \\
\text { pragmatic } \\
\text { solution that } \\
\text { works. }\end{array}$ & $\begin{array}{l}\text { Tend to use enterprise } \\
\text { solutions } \\
\text { - Open to pragmatic open } \\
\text { source or free solutions } \\
\text { - Very flexible approach } \\
\text { - Limited capital spend }\end{array}$ & $\begin{array}{l}\text { - Niche markets can } \\
\text { be highly profitable } \\
\text { with flexible } \\
\text { bespoke solutions } \\
\text { not easily offered } \\
\text { by large SP's }\end{array}$ \\
\hline $\begin{array}{l}\text { Emerging } \\
\text { Markets }\end{array}$ & $\begin{array}{l}\text { - May internally } \\
\text { develop since } \\
\text { labour is cheap } \\
\text { vs. COTS }\end{array}$ & $\begin{array}{l}\text { Often purchase locally } \\
\text { or in a lo-cost market } \\
\text { because they cannot } \\
\text { afford Tier } 1 \text { solutions. }\end{array}$ & $\begin{array}{l}\text { - Have clever staff } \\
\text { able to create local } \\
\text { workable solutions. }\end{array}$ \\
\hline
\end{tabular}

Despite the overall reduction in spending due to the burst of the 'dot.com bubble', the first and second tier customers continue to represent a cosy market for their incumbent OSS suppliers due to the high barriers to entry and the stranglehold OSS systems on the service providers' internal operations. The cost of replacing any one of these systems is too prohibitive for most telecoms operators to consider and although emerging suppliers would very much like to address this market, they cannot easily offer a value proposition which would justify the 
disruption in altering the current status quo.

\subsection{The Role of Standards}

Standards have always played a significant role in Telecommunications product development. However the rate of change in the industry has required a move from the paper standards development processes originally followed by the PTTs through the CCITT towards less bureaucratic mechanisms pioneered by the IETF which require working implementations before a standard is accepted [12]. Increasingly standards bodies such as the DMTF are promoting the use of open source to both develop and promote standards [13].

The very nature of the network equipment market requires a commitment to interoperability through standardised interfaces. As a result, it would be very unusual today to find new network equipment introduced by a vendor which did not interoperate at least at a basic level with other network equipment from its first day of introduction.

Unfortunately, the same level of commitment to interoperability does not exist with respect to standardisation of components within the OSS space. Every OSS component follows a different design pattern and requires specific staff training in its use. Integration requires a detailed and difficult mapping of functionality between components. The time to integrate any solution increases exponentially with the number of systems because each component's interfaces have to be considered separately and not as part of a pre-integrated framework. Historically a number approaches have emerged to try and address these issues.

Firstly, over the years many attempts have been made to simplify OSS integration using public standards (TMN, OSI, TINA-C to name a few) but none have had sufficient market adoption to guarantee component interoperability without significant integration work.

Secondly, larger vendors have attempted to create OSS frameworks (such as TeMIP or OpenViews etc) to simplify integration of third party 'plug-in' components. These frameworks are proprietary and again, the lack of critical mass has prevented clear de-facto standards from emerging across the industry.

Finally, as a stop-gap, the larger system integrators have promised to considerably reduce the integration time for their customers by making the prior investment of building their own reference OSS architectures using pre-integrated components from different OSS vendors. This significant investment is hard for smaller integrators to emulate but the benefit of this approach breaks down when customers go beyond vanilla solutions or require localised integration to legacy systems.

Lately there has been a realisation that the telecoms OSS market alone does not have the volume to drive its own software standards. This is reflected in the thinking behind Telemanagement Forum's Next Generation Operations Support System (NGOSS) [14]. NGOSS specifies a framework for OSS integration which can bridge legacy OSS technologies with the new component development standards reaching critical mass in the enterprise world (i.e. J2EE, .NET or SOA 
and web services). Similar thinking drives OSS/J [15], an open standard initiated by SUN for implementing NGOSS compliant solutions leveraging J2EE [16] .

If these new standards reached critical mass, they would potentially represent a significant market discontinuity. Firstly they would allow proven low-cost components from the enterprise world to be easily integrated into the OSS environment. Secondly, they would represent a lowering of the barrier to entry for non-incumbent component vendors - effectively commoditising parts of the OSS market. And thirdly, they could provide a framework for some of the service providers' currently huge internal investment in software development to be shared across the Telecommunications industry.

It is in harnessing this last possibility, by encouraging internal development groups to work to emerging common architectural standards, that there exists the potential for an industry wide open solution development initiative.

\subsection{The Operations Systems Gridlock}

Commentators such as Lee and Ben Natan [17] would observe that one of the biggest costs and roadblocks to telecoms agility is the current industry-standard OSS suite. A major headache in the introduction of even a simple new service is the management of the supply chain to orchestrate the changes required across multiple OSS products.

Each COTS OSS component has its own commercially driven roadmap which guides the core development of the product. Large service providers can demand product customisations in order to meet the needs of the solutions offered to their customers. Unfortunately, despite many promises (often made in good faith), there is no guarantee that any customisations will be forwards compatible with the next release of the product or that the product will actually follow the original roadmap outlined by the vendor. Thus the Service Provider needs to spend a great deal of energy managing the roadmaps of his selected COTS product vendors in order to try and fulfil a long term plan.

An additional problem has been caused by the current market configuration. The various COTS systems currently available have traditionally been designed to fit a particular purchasing and marketing strategy which emerged to support early OSS standards. The ITU Telecommunications Management hierarchy [18] provided a useful nomenclature over the last 20 years for specifying systems in the Element, Network and Service Management and the Business Support Systems layers. However its use has had the unfortunate side effect of creating a market where the most established products have been packaged to represent components described in this telecommunications hierarchy. The early standards never considered modern enterprise concepts such as separate work flows running across components and the fact that the same components might be required to manage services across multiple network technologies. While the TMN nomenclature remains useful, it is too rigid a model to think about the realities of today's very complex process flows in a telecoms infrastructure.

Thus it can be argued that this has created two market problems. Firstly, the Tier 1 operators have chosen a set of products for specific purposes and are 
unwilling to let these products be developed into areas beyond their core functionality. Secondly, the Tier 1 software vendors have made a huge investment in establishing product brands for products which map onto the legacy view of telecommunications management and are unwilling to un-bundle the functionality into separate components in order to better match the needs of their customers. Nobody wants to give up 'functionality footprint' to a competitor.

In effect we have a market gridlock which makes it very difficult to establish the viability of a next generation solution in the face of so many long term investment decisions and vested interests in maintaining the status quo.

\subsection{A Summary of the problem}

In summary, OSS Software development represents a significant and rising cost to the Telecommunications industry. A very high proportion of OSS development is currently done in-house by service providers - presumably because they cannot find or cannot afford suitable software in pre-built COTS products. COTS products still only account for $1 / 3$ of the OSS software procurement activity and where large service providers purchase COTS solutions, they invariably modify them significantly before deployment. The fact that the current set of COTS solutions do not seem to meet all the needs of most service providers suggests that the current structure of the industry and the packaging of COTS components make it very hard for service providers to create useful solutions without additional development. There seems to be a fundamental problem with the current market approach to managing requirements across the solution space.

Although the potential benefits of emerging standards such as NGOSS and $\mathrm{OSS} / \mathrm{J}$ are great, the reality is that the industry remains to be convinced that these are the right approach. There is an urgent need for more proof points to convince the industry to adopt these standards. If a component approach using NGOSS and $\mathrm{OSS} / \mathrm{J}$ could be demonstrated to work as a means to enable open development of useful components 'by the industry and for the industry', it could also lead to a significantly more efficient use of the service providers internal development resources. We now turn to considering how shared open component development across the industry might be achieved.

\section{Open OSS - A feasibility study into Open Source OSS}

\subsection{The potential benefits of open development}

The software industry has woken up to the potential of open source and several commentators are proposing best practise for open source development. [19,20,21]. Martin Fink the Director of open source projects at Hewlett Packard has written on the commercial opportunities of open source [22]. He sees open source as a tool to help the industry create better solutions to common problems. On a philosophical level, objections have been raised to open source on the grounds that it will kill innovation in the software industry since it is being used as a way to market 'failed software products' [23]. However this ignores the fact that the business model relies 
not on software sales but on services. By feeding and watering the plant, many people get to harvest the fruit.

In a recent UK survey, into the perception of open source software by Chief Information Officers [24], 16\% of the CIOs surveyed said they were actively looking at open source solutions now. This suggests that there is a growing enterprise awareness of the potential value of open source solutions. The telecommunications community has been traditionally more sceptical but a number of service providers are becoming interested in exploring the potential of open source alternatives to internal development. A 2001 Eurescom project suggested a number of benefits could be derived from open source in the Telecoms industry[25,26]. A number of equipment vendors have identified similar potential benefits of open source as a means to simplify the problem of mapping vendor specific equipment functions to a more generic OSS infrastructure. This is one of the drivers behind the Ericsson, Motorola, NEC, Nokia and Siemens Co-operative Open OSS Project [27].

Academia now appears as the second major source of open source software after independent developer communities [28]. Open source could also provide a mechanism for academia to share work with commercial partners allowing more brain power to be applied to the OSS problem.

\subsection{Open Development and the COTS Vendors}

The creation of an Open Source OSS project could be viewed as a threat to the incumbent ISVs. However, we would rather position this project as an opportunity for the Telecoms OSS industry. Much of the attention given to the phenomenon of open source software has focused on the economic issues related to free software licensing, rather than on the value of open development techniques as a means to develop useful components for an industry. We wish therefore to find a way to test whether open development could be used effectively in the Telecommunications industry to prove the value of emerging management standards and potentially to create useful components for the industry.

Enterprise management standards such as those from the DMTF are already being implemented in open source and are moving into the enterprise mainstream. Harvard professor, Clayton Christensen has identified that Open Source represents a Disruptive Technology [29,30]. Initially open source products are low specification but they can bring to the market simpler and more affordable products that allow a whole new population of people to begin using them. However because the open source innovation trajectory is so steep, what begins a simple application can ultimately intersect with the mainstream. The danger is that ignoring the enterprise approach to development could later leave the incumbent Telecoms OSS vendors struggling to catch up.

Conversely, NGOSS envisages a framework providing common services to a variety of OSS components. Most COTS OSS products in production today contain duplicated functions which represent a cost to maintain and which are generally done better by mainstream enterprise solutions. A common framework of services could allow OSS COTS vendors to concentrate on exploiting their lead in their 
high value IPR which addresses telecoms niche functionality such as alarm collation or SLA management while avoiding wasted effort on 'vanilla' functionality. This project seeks to explore what that common set of services might be and if possible explore implementing these services in Open Source.

\subsection{Open OSS Project Objectives}

The two pillars of the proposed Open OSS project are the exploration of open source / free software development techniques combined with the promotion of emerging Network Management standards across the telecommunications industry. By this means we hope to demonstrate to the industry the value of the emerging standards and of new ways of doing business. The basic premise of the Open OSS project is that the telecommunications industry needs to modify its competitive behaviour in order to co-operate in developing solutions which meet the common base needs of the industry. A mechanism is required to allow the OSS supply chain to be collapsed across the organisational boundaries between blue sky researchers, equipment vendors, OSS vendors, systems integrators and service providers.

The need for co-operation across the industry has already been recognised by the Telemanagement Forum in that they sponsor a number of 'Catalyst' projects on a 6 monthly basis as a means for vendors and service providers to produce 'proofs of concept' of NGOSS principles for the industry. Strassner considers the use of industry based Catalyst projects an essential part of the process of developing and proving NGOSS standards [31]. However to date, implementing a Catalyst has involved taking a selection of industry standard COTS systems, integrating them using NGOSS interfaces (usually OSS/J) and demonstrating them managing a pilot network or service. Few artefacts or reports on the project are made publicly available. Further more, it is very difficult for the industry or academia to reproduce these experiments without access to the software products which were used in the demonstration.

Although limited, the Catalysts do provide value because many of the participants in the Catalysts are also participants in the NGOSS and OSS/J standardisation process and there is a route for detailed technical feedback into the standards. However there would be great value in being able to create an open environment in which many more players could participate in evaluating the emerging technology. The hope is that the Open OSS project will make it possible for researchers to more easily build a reference solution demonstrating NGOSS principles.

\subsection{Initiating the Project}

Unlike many academic research activities the Open OSS project is being designed explicitly to facilitate industry collaboration in creating common OSS components. The research objective is to investigate whether this sort of collaboration can produce more effective industry OSS solutions than the more traditional OSS acquisition and product management processes. This may be thought of as a second order research objective which runs in parallel with and provides additional proof points for the core research supporting the development of the NGOSS 
standards. The contribution this project makes towards adoption of the standards will be one success factor by which it should be measured.

To be successful, this project will first require that an industry collaboration is set up with clear benchmarks for success. Open development implies that the parties can choose to participate or not and the motivation for participating will be different in each case. In a successful project it is thus vital that the aspirations of all the participating parties are well understood and clearly addressed by the project. This includes understanding the motivation of individuals who may be champions of the project within their employers organisations.

Chapman and Ward have suggested that a key factor in successfully managing the risks associated with a collaborative project is an understanding of the motivations of the stakeholders involved [32]. We have used part of their motivation framework to categorise the generic motivations of the various stakeholders in an open source OSS project. The results of having discussed this project with a number of potential stakeholders are summarised in Table 2.

Table 2: Motivation Analysis - applied to Open OSS project

\begin{tabular}{|c|c|c|}
\hline \multicolumn{3}{|c|}{ Who: Service Providers } \\
\hline Why (motives) & What (design) & Potential Risks \\
\hline \multirow[t]{3}{*}{$\begin{array}{l}\text { More } \\
\text { effective } \\
\text { spending on } \\
\text { OSS SW }\end{array}$} & $\begin{array}{l}\text { Lower cost alternative } \\
\text { to COTS solutions }\end{array}$ & $\begin{array}{l}\text { - Litigation issues - 'Viral licences'. } \\
\text { - Lack of commercial support model } \\
\text { - Organisational resistance open SW } \\
\text { - Lack of suitable components }\end{array}$ \\
\hline & $\begin{array}{l}\text { Better requirements } \\
\text { management and } \\
\text { roadmap control }\end{array}$ & $\begin{array}{l}\text { - Lack of credible lead architects to } \\
\text { represent SP's to developers } \\
\text { - No guaranteed open source roadmap } \\
\text { - Loss of OSS competitive advantage }\end{array}$ \\
\hline & $\begin{array}{l}\text { Industry Development } \\
\text { of OSS components }\end{array}$ & $\begin{array}{l}\text { - some partners 'free-ride' } \\
\text { - One user left supporting component }\end{array}$ \\
\hline \multirow[t]{3}{*}{$\begin{array}{l}\text { Reduced } \\
\text { integration } \\
\text { costs }\end{array}$} & $\begin{array}{l}\text { Promote emerging } \\
\text { OSS framework } \\
\text { integration standards }\end{array}$ & $\begin{array}{l}\text { - Standards not sufficiently mature } \\
\text { - Interim design not in standards } \\
\text { - Standards never widely adopted }\end{array}$ \\
\hline & $\begin{array}{l}\text { Encourage COTS OSS } \\
\text { componentisation }\end{array}$ & $\begin{array}{l}\text { - Project not taken seriously by COTS } \\
\text { vendors }\end{array}$ \\
\hline & $\begin{array}{l}\text { Rapid development } \\
\text { using MDA-like tools }\end{array}$ & $\begin{array}{l}\text { - Tools immature - significant re- } \\
\text { working needed later on }\end{array}$ \\
\hline $\begin{array}{l}\text { Reduced Ops } \\
\text { costs }\end{array}$ & $\begin{array}{l}\text { Reduce specialist staff } \\
\text { training needs }\end{array}$ & $\begin{array}{l}\text { - Chosen technologies never reach wide } \\
\text { industry acceptance. }\end{array}$ \\
\hline \multicolumn{3}{|c|}{ Who: Systems Integrators } \\
\hline Why (motives) & What (design) & Potential Risks \\
\hline $\begin{array}{l}\text { Thought } \\
\text { leadership }\end{array}$ & $\begin{array}{l}\text { Promoting capabilities } \\
\text { in Open Source and } \\
\text { OSS frameworks }\end{array}$ & $\begin{array}{l}\text { - Integrator fails to generate industry } \\
\text { thought leadership } \\
\text { - Project failure creates negative impact }\end{array}$ \\
\hline $\begin{array}{l}\text { Develop } \\
\text { services to } \\
\text { deliver Next } \\
\text { Gen OSS } \\
\end{array}$ & $\begin{array}{l}\text { Processes for NGOSS } \\
\text { component Selection, } \\
\text { Assembly Deployment }\end{array}$ & $\begin{array}{l}\text { - NGOSS / OSS/J solutions gain limited } \\
\text { market acceptance } \\
\text { - Conflict if SI is perceived as } \\
\text { competing with COTS vendors }\end{array}$ \\
\hline
\end{tabular}




\begin{tabular}{|c|c|c|}
\hline Why (motives) & What (design) & Potential Risks \\
\hline $\begin{array}{l}\text { Concentrate } \\
\text { on core } R \& D\end{array}$ & $\begin{array}{l}\text { create a commons of } \\
\text { non core technologies }\end{array}$ & $\begin{array}{l}\text { - commons not adopted by industry } \\
\text { - commons does not support } \\
\text { differentiating features }\end{array}$ \\
\hline $\begin{array}{l}\text { Market OSS } \\
\text { middleware }\end{array}$ & $\begin{array}{l}\text { NGOSS / OSS/J proof } \\
\text { points \& components }\end{array}$ & $\begin{array}{l}\text { - Conflict if middleware vendor is } \\
\text { perceived as competing with COTS }\end{array}$ \\
\hline \multicolumn{3}{|c|}{ Who: Academia } \\
\hline Why (motives) & What (design) & Potential Risks \\
\hline $\begin{array}{l}\text { Closer } \\
\text { industry } \\
\text { contact }\end{array}$ & $\begin{array}{l}\text { Building a project } \\
\text { which acts as a 'living } \\
\text { laboratory' for } \\
\text { research consortia }\end{array}$ & $\begin{array}{l}\text { - Potential disputes over IPR } \\
\text { exploitation } \\
\text { - Potential conflict over wider } \\
\text { publication of research results }\end{array}$ \\
\hline $\begin{array}{l}\text { Apply OSS to } \\
\text { other problems }\end{array}$ & $\begin{array}{l}\text { Manage advanced web } \\
\text { services / Grid etc }\end{array}$ & $\begin{array}{l}\text { - Other industries create own solutions } \\
\text { and don't see value of telecoms OSS }\end{array}$ \\
\hline \multicolumn{3}{|c|}{ Who: Individual developers / Students } \\
\hline Why (motives) & What (design) & Potential Risks \\
\hline $\begin{array}{l}\text { Increase job } \\
\text { interest and } \\
\text { employability }\end{array}$ & $\begin{array}{l}\text { - Avoid orphan skills } \\
\text { - Raise job profile } \\
\text { - Make current } \\
\text { development job } \\
\text { easier }\end{array}$ & $\begin{array}{l}\text { - Project doesn't deliver value to } \\
\text { employee's business } \\
\text { - Individual stuck on 'maintenance' vs. } \\
\text { new design } \\
\text { - Too much churn in community } \\
\text { membership }\end{array}$ \\
\hline
\end{tabular}

As with any product solution, an open source solution will need marketing to gain a viable user base. Fink [22] considers it very important that the project is launched effectively otherwise it is unlikely to reach a critical mass of developers and users. It will be necessary to ensure that potential collaborators and end users are well informed and able to participate usefully in the project from day one. This will require commitment to building a viable community and also that clear attention is given to the 'marketing mix' of the project as outlined in Table 3

Table 3: A marketing mix evaluation of open OSS project requirements

\begin{tabular}{|c|c|c|c|}
\hline Mix & \multicolumn{2}{|c|}{ Evaluators question } & Requirement \\
\hline Price & \multicolumn{2}{|c|}{$\begin{array}{l}\text { Does open development reduce } \\
\text { the cost through solution life }\end{array}$} & $\begin{array}{l}\text { Trial projects must provide reduced } \\
\text { cost ownership proof points }\end{array}$ \\
\hline Promotion & \multicolumn{2}{|c|}{$\begin{array}{l}\text { Does open source provide a } \\
\text { differentiating market channel }\end{array}$} & $\begin{array}{l}\text { Marketing to ensure high industry } \\
\text { visibility (use co-marketing etc) }\end{array}$ \\
\hline Place & \multicolumn{2}{|c|}{$\begin{array}{l}\text { Where can the solution be } \\
\text { obtained? }\end{array}$} & $\begin{array}{l}\text { Need a well known place (web site) } \\
\text { to find the work }\end{array}$ \\
\hline People & \multicolumn{2}{|c|}{$\begin{array}{l}\text { Are a credible development } \\
\text { team working on the solution? }\end{array}$} & $\begin{array}{l}\text { Need a governance model which } \\
\text { links respected industry players. }\end{array}$ \\
\hline \multirow[t]{3}{*}{$\begin{array}{l}\text { Physical } \\
\text { Evidence }\end{array}$} & Process & $\begin{array}{l}\text { Open development } \\
\text { Process/Culture }\end{array}$ & $\begin{array}{l}\text { Plan how a viable community can } \\
\text { be developed around project }\end{array}$ \\
\hline & $\begin{array}{l}\text { Physical } \\
\text { Goods } \\
\text { (Product) }\end{array}$ & $\begin{array}{l}\text { Can the packaged } \\
\text { solution be easily } \\
\text { obtained and used? }\end{array}$ & $\begin{array}{l}\text { Packaging/distribution (web } \\
\text { download) easing solution use. } \\
\text { Initial release to be well documented } \\
\text { and fit for purpose. }\end{array}$ \\
\hline & Services & $\begin{array}{l}\text { Are there sufficient } \\
\text { services for the } \\
\text { solution? }\end{array}$ & $\begin{array}{l}\text { Need support mechanisms - web } \\
\text { logs, FAQ's and ultimately a } \\
\text { commercial support offering. }\end{array}$ \\
\hline
\end{tabular}


Open Source projects are often characterised as having no strict plans, open code access and external developers. However we would argue that this describes projects once they have reached equilibrium. Even then, there is usually a tacit understanding of a roadmap among the core architects even if this is not published.

Fink believes one of the major reasons why Open Source projects fail is that they release code too early and they do not have an architecture which makes it easy for others to contribute, citing this as a major issue in the early launch of the Mozilla project by Netscape. He believes that a key requirement for success is that the first code released is relatively bug free and can be easily understood and used by others. Therefore it is important to ensure that the open OSS project has a strong core team and coherent architecture before it is put in the public domain. Additionally, the solution should leverage successful Open Source components which are already established in the market place.

\subsection{Research Philosophy and Strategy}

Telecommunications Network and Service Management, rightly understood, is both a Technical and a Business discipline. Too often research in this field has been technology led to the extent that while elegant solutions have been created, they have been of limited practical value because they were developed with an incomplete understanding of the broad systems, organisation and business environment. A significant factor in the success of a network management system is an appreciation of the motivation, skills and psychology of those who are being asked to use the systems to manage the service.

The Open OSS project is about determining whether a particular approach to solution development will work in the Telecommunications industry. Consequently the research will draw on business and engineering analyses of the problem. However the key factor in this research is that rather than simply observe the industry, we wish to use this research to actually catalyse a change in the way the industry does business. In order to do this we will actively be seeking significant industry partners whose participation will create an opportunity for change within the industry. Finding these partners will of course be a difficult and risky challenge.

Table 4: Open OSS as an Action Research Project

Action Research Qualities

1. Change Management

The purpose of action research is the management of a change

2. Practitioner Involvement

Action research seeks practitioners involvement in the research

3. Generalised Implications

Action research should have implications beyond immediate project

\section{Open OSS Implications}

Open OSS should change industry attitude to collaborative development

Open OSS should seek to build an open project with users in the SP community.

Open OSS should seek to generalise the results across the Telecoms industry.

The underlying research strategy for this project will therefore be that of Action Research as discussed by Saunders [33]. Action Research is a strategy 
whereby the researcher is not an inert observer but actively involved in a project to bring about change. Table 4 illustrates what this means for Open OSS. In practice this means that all of the technical research undertaken must be informed by and tested against the realities of industry.

\subsection{The Open OSS Project Outline}

The Open OSS initiative is initially planned with a life of three years beginning in Q3 2004. The first deliverable from the initiative will be a Telemanagement World Catalyst proof of concept in May 2005. Details of deliverables and participants can be reviewed in the Project Charter [34].

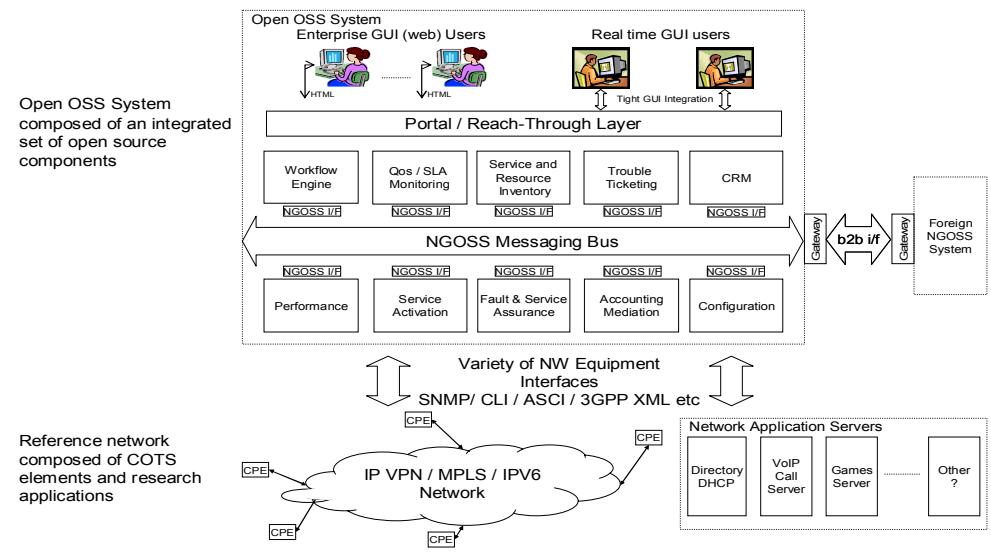

Figure 1: Open OSS Test Bed Components

In the long term, the project will lead to a simple Telecoms OSS reference architecture and test environment as outlined in Figure 1. In this diagram the NGOSS I/F represents the NGOSS contract[35]. In practice in the first instance, this will be implemented using OSS/J interfaces, on the understanding that OSS/J already represents a technology specific implementation of NGOSS [16]. The test environment will be available to the industry as an aid to the adoption of NGOSS and OSS/J. In addition the project will produce training collateral and worked examples to assist with the uptake of the NGOSS methodology and lifecycle[36]. It is also intended that the test environment will be available for other research activities. One early example of this is the intention to leverage the test environment to assist a sister catalyst project exploring the use of MDA tools to deliver NGOSS[37]

\section{Conclusions}

We have characterised how the problems within the current OSS market slow the innovation of next generation OSS solutions. We have described how open development of NGOSS solutions could facilitate change in the OSS market 
landscape and make an important contribution to the rapid adoption of NGOSS by industry practitioners.

The first deliverable of the Open OSS project will be a 'Catalyst' proof of concept involving industrial and academic partners to be demonstrated at Telemanagement World in May 2005. The partners are currently planning the next stage of the project which will expand the community towards an open source model.

\section{Acknowledgments}

We would like to thank BT and Invocom for their sponsorship of this project.

\section{References}

[1] R. A. Guth. 1-10-2004. Microsoft Could Lose 1996 Patent That May Hinder Linux Software. The Wall Street Journal, Section B4

[2] E. S. Raymond. 1999. The Cathedral and the Bazaar. Cambridge : O'Reilly,

[3] University of Southampton. 2004. OMII - Open Middleware Infrastructure Institute. www.omii.ac.uk

[4] University of North Carolina. 2004. The Open Source Research Team. http://www.ibiblio.org/osrt/

[5] University of California Irvine. 2004. ISR : Open Source Software Development. http://www.isr.uci.edu/research-open-source.html

[6] University College Cork. 2004. Open Source Research Resources. http://opensource.ucc.ie

[7] Universidad Rey Juan Carlos Madrid. 2004. Libre Software Engineering Research. http://barba.dat.escet.urjc.es/

[8] MIT. 2004. Free/Open Source Research Community at MIT. http://opensource.mit.edu/

[9] European Union. 2004. Calibre - Coordination Action for Libre software (EU) FW6 Project. http://www.calibre.ie/

[10] L. Goldman. 2004. TMW Nice 2004: The Global OSS Landscape. OSS Observer http://www.ossobserver.com/library/library12.pdf

[11] L. Goldman. 2004. TMW Asia 2004: OSS Market Overview - An Asian Perspective. OSS Observer http://www.tmforum.org/browse. asp? catID $=2103 \&$ sNode $=2103 \&$ Exp $=Y \& 1$ inkID $=29555$

[12] IETF. 1996. RFC: 2026 The Internet Standards Process. http://www.ietf.org/rfe/rfc2026.txt

[13] DMTF. 2004. DMTF WBEMsource initiative: open source enterprise management RI. http://www.wbemsource.org/

[14] Telemanagement Forum. 2004. NGOSS Overview. http://www.tmforum.org/browse.asp?catID $=1912$

[15] SUN Microsystems. 2001. The OSS Through Java Initiative. Simplifying integration with common API's. http://www.ossj.org/learning/docs/wp_common_api.pdf

[16] Telemanagement Forum. 2004. OSS through Java as an Implementation of NGOSS A White Paper. http://www.tmforum.org/browse.asp?catID=1923\&linkID=29240 
[17] J. Lee and R. Ben Natan. 2002. Integrating service level agreements. Indianapolis, Ind.; Wiley Pub

[18] International Telecommunications Union ITU-T. 2000. ITU-T M3000 Series $T M N$. http://www.itu.int

[19] J. Feller and B. Fitzgerald, 2002, Understanding Open Source Software development, London : Pearson Education,.

[20] K. Fogel and M. Bar, 2001, Open source development with CVS, Scottsdale, AZ : Coriolis Group Books,.

[21] J. Sandred, 2001, Managing open source projects : a Wiley tech brief, New York ; Chichester : Wiley,

[22] M. Fink, 2002, The business and economics of Linux and Open Source, Upper Saddle River, N.J., Prentice Hall PTR, London

[23] K. M. Schmidt and M. Schnitzer. 2003. Public subsidies for open source? London : Centre for Economic Policy Research

[24] Open Forum Europe. 2003. Market Perception Analysis of Open Source Software . http://www.openforumeurope.org

[25] A. Gavras. 2001. Eurescom P1044 Report: A strategic study on the use of Open Source in a telecommunications operator's environment. Eurescom.Heidelberg, Germany http://www.eurescom.de/public/projects/P1000-series/p1044/default.asp

[26] J. P. Pereira, V. de Matos, P. Chainho, G. Lin and S. Mäkinen. 2001. Eurescom P1044 Report: Technical Evaluation of Open Source Products. Eurescom.Heidelberg, Germany

[27] Nokia. 11-10-2004. Press Release: CO-OP Co-operative Open OSS Project October 11, 2004. http://press.nokia.com/PR/200410/963794 5.html

[28] J. M. Dalle and G. Rousseau. 2004. Towards an Open Source Technology Transfer. Proc.4th Workshop on Open Source SW Eng 2004. IEEE Computer Society http://opensource.ucc.ie/icse2004/index.html

[29] C. M. Christensen. 2003. The Innovator's Dilemma. Harper Business Essentials New York :

[30] C. M. Christensen. 16-3-2004. Open Source: Capturing the Upside While Avoiding the Downside. OSBC Transcript at http://www.itconversations.com/shows/detail135.html

[31] J. C. Strassner. 2004. Policy-Based Network Management, Solutions for the Next Generation. 466-470., Morgan Kauffmann.San Francisco

[32] C. Chapman and S. Ward. 2003. Project Risk Management. John Wiley and Sons Ltd.Chichester

[33] M. Saunders, P. Lewis and A. Thornhill, 2003, Research Methods for Business Students 3rd Edition, Prentice Hall, Harlow.

[34] Telemanagement Forum. 2004. Open OSS - Project Charter. www.tmforum.org

[35] Telemanagement Forum. 2004. TMF053b: NGOSS Architecture Technology Neutral Specification Contract Description: Business and System Views.

[36] Telemanagement Forum. 2004. NGOSS Lifecycle Methodology - GB927

[37] Telemanagement Forum. 2004. NGOSS/MDA: Realizing NGOSS using MDA Project Charter. www.tmforum.org 